\title{
Chemical and Biological Properties of Paddy Soil Treated with Herbicides and Pyroligneous Acid
}

\author{
H. R. L. Benzon ${ }^{1,2}$, M. R. U. Rubenecia ${ }^{1}$, Jr. V. U. Ultra ${ }^{3} \&$ Sang Chul Lee ${ }^{1}$ \\ ${ }^{1}$ School of Applied Biosciences, Kyungpook National University, Daegu, Korea \\ ${ }^{2}$ National Institute of Molecular Biology and Biotechnology, UPLB, College, Laguna, Philippines \\ ${ }^{3}$ College of Natural Sciences, Catholic University of Daegu, Gyeongsan, Korea \\ Correspondence: Sang Chul Lee, School of Applied Biosciences, Kyungpook National University, Daegu \\ 702-701, Korea. Tel: 53-950-5713. E-mail: leesc@knu.ac.kr
}

Received: December 14, 2014 Accepted: January 25, 2015 Online Published: March 15, 2015

doi:10.5539/jas.v7n4p20 URL: http://dx.doi.org/10.5539/jas.v7n4p20

\begin{abstract}
In this study, the effect of different herbicide $\mathrm{x}$ pyroligenous acid mixtures on soil chemical and biological properties was evaluated in order to elucidate its potential impacts on nutrient availability and soil quality. The experiment was conducted under greenhouse conditions consisted of 100-fold diluted wood vinegar (100 WV), $50 \%$ BCB (Bentazone cyhalofop-butyl), 100\% BCB, 50\% BCB $+100 \mathrm{WV}, 50 \% \mathrm{BCB}+250 \mathrm{WV}$ and $50 \%$ $\mathrm{BCB}+500 \mathrm{WV}$ applied against Echinochloa crusgalli. Ten days after herbicide application, the chemical properties were altered and the changes were influenced by the amount of WV dilutions. The soil $\mathrm{pH}$ was near neutral to slightly alkaline coupled with decreased electrical conductivity (EC). The total carbon, available phosphorous, exchangeable magnesium, exchangeable sodium, exchangeable calcium, exchangeable potassium and cation exchange capacity (CEC) were relatively lower compared to the control. Biolog ${ }^{\text {TM }}$ assay showed that different treatments resulted to variable microbial activity, Shannon-Weaver index and richness of carbon utilization potential. Principal component analysis showed segregation of samples based on extracted principal components indicating variable carbon utilization potential due to different treatments combination. Correlation analysis between soil and microbial properties revealed that Principal Component 2 has negative correlation with $\mathrm{pH}$ and available P. On the other hand, Principal Component 3 was positively correlated with total $\mathrm{C}$, exch. Ca, $\mathrm{Mg}, \mathrm{Na}$, and $\mathrm{CEC}(0.475,0.490,0.555,0.489$, and 0.517 , respectively). Application of pyroligneous acid combined with herbicides resulted to changes in soil chemical and biological characteristics which may have unique implications on nutrient availability and overall soil quality.
\end{abstract}

Keywords: bentazone cyhalofop-butyl, Biolog ${ }^{\mathrm{TM}}$, pyroligneous acid, soil chemical and biological properties

\section{Introduction}

The continuous use of environmentally persistent herbicides and other synthetic agricultural chemicals posed great risks to soil and water contamination. A viable alternative pesticide that is equally effective and less harmful to the environment is in demand. The role of pyroligneous acids (PA), also as plant and soil treatments gained the attention of research enthusiasts. Pyroligneous acid is a dark brown solution obtained as a by-product of wood carbonization. Large number of substances has been found in the pyrolysis liquids from different resources. The detected substances from the acids belong to different classes of organic compounds, namely, aldehydes, ketones, alcohols, organic acids, esters, derivatives of furan and pyran, phenolics, hydrocarbons and nitrogen compounds, in which the major ones are organic acids and phenolics (Souza et al., 2012). These compounds are known to increase herbicide efficacy (Kim et al., 2001).

The acidic nature of PA may have an effect on displacement of ions from soil exchange complex. An advantage of this would be improved nutrient availability. However, increased displacement would possibly result to leaching of substances through the soil profile (Jones, 1998; Andrade, 2003). For that reason, studies on the impact of the use of this kind of product are of great agricultural and environmental importance, and absolutely necessary to support the correct and safe application of chemicals (synthetic or alternative agricultural supplies) on the soil.

Soil microorganisms play an important role in soil-plant-herbicide-fauna-man interactions. They participate in 
herbicide degradation and activity, they may serve as bioindicators of changes in soil biological activity and, some microbial species may be used as bioherbicides. The microbial biomass can also represent a large pool of nutrients especially on less fertile sites (Giardina et al., 2000). Microorganisms can act as sinks, during immobilization and sources, during mineralization of labile nutrients (Garcia-Oliva et al., 1998; Stenstrom et al., 1998). The soil biota activity can be stimulated as an indirect result of the chemical changes in the soil.

There is no or limited scientific information with regard to the influence of pyroligneous acids coupled with synthetic herbicides on soil chemical and biological properties. Hence, the objective of this study was to evaluate the combined effect of different herbicide and pyroligenous acid mixtures on soil chemical and biological properties in order to elucidate its potential impacts on nutrient availability and soil quality.

\section{Methods}

\subsection{Experimental Set Up}

The experiment was conducted under greenhouse conditions at the Agricultural Experiment Station and Research Facility, College of Agriculture and Life Sciences, Kyungpook National University, Daegu, South Korea. The experimental set up was in a Completely Randomized Design (CRD) with three replications.

The treatments were: T1-Control, T2-100 WV (100-fold diluted wood vinegar), T3-50\% BCB (Bentazone cyhalofop-butyl), T4-100\% BCB, T5-50\% BCB+100 WV, T6-50\% BCB+250 WV (250-fold diluted wood vinegar) and $\mathrm{T} 7-50 \% \mathrm{BCB}+500 \mathrm{WV}$ (500-fold diluted wood vinegar). The herbicide $\mathrm{BCB}$ and the WV was applied singly or consecutively by spraying. The wood vinegar (Table 1) was obtained from a local distributor. The planting media was composed of 1:1 paddy and sandy soil $(\mathrm{ph}=6.69, \mathrm{EC}=72.4 \mathrm{uS} / \mathrm{cm})$. Water depth in pots was maintained at $3 \mathrm{~cm}$ on the soil surface during the experiment period. Treatment application was done at 2 to 3 leaf growth stage, approximately 6 to 8 days after transplanting of barnyard grass. The experiment was terminated 10 days after treatment application.

Table 1. Physical and chemical components of wood vinegar

\begin{tabular}{ll}
\hline Item & Wood vinegar \\
\hline $\mathrm{pH}$ & 2.97 \\
Electrical conductivity & $2313 \mathrm{uS} / \mathrm{cm}$ \\
Transparency & Transparent \\
Color & Golden brown \\
Methanol & $0.31 \%$ \\
Phenolic compounds & $2.44 \%$ \\
Propanoic acid & $0.89 \%$ \\
Acetic acid & $9.95 \%$ \\
\hline
\end{tabular}

Typically, wood vinegar is high in low-molecular weight acids (formic and acetic), alcohols (methanol) and aldehydes, which can serve as a carbon and energy resource for prototrophic bacteria occurring in the soil (Focht, 1999 as cited by Hagner, 2013). However, the high acidity, methanol and phenol content have strong bactericidal effect at a high concentration. Therefore, wood vinegar if applied in correct concentration, can enhance the soil biological properties.

\subsection{Soil Sample Preparation and Analysis}

Immediately after sampling, soil samples for microbial characterization were stored at $4{ }^{\circ} \mathrm{C}$ until analysis while samples for chemical analyses were air-dried, ground, and passed through $2 \mathrm{~mm}$ sieve. Soil pH and EC were determined in 1:5 soil-water ratio (Thermo Scientific Orion Star A215 Benchtop pH/EC meter). Total organic C was determined using an elemental analyzer (ThermoFisher Flash 2000). Available P was determined following the method described by Pierzynski (2000). Air-dried soil samples $(2.0 \mathrm{~g})$ were added in $20 \mathrm{~mL}$ Bray and Kurtz P-1 extracting solution $\left(0.025 \mathrm{M} \mathrm{HCl}\right.$ in $\left.0.03 \mathrm{M} \mathrm{NH}_{4} \mathrm{~F}\right)$ and were placed in a mechanical shaker $(200$ or more epm) for 5 minutes at room temperature. The extracts were filtered through Whatman No. 42 filter paper and were analyzed for phosphorus by ICP-MS (PerkinElmer NexION 300X). Soil exchangeable bases were extracted through ammonium acetate method according to Brix (2008). Air-dried soil samples (2.0 g) were added in $20 \mathrm{~mL}$ $1 \mathrm{M} \mathrm{NH}_{4} \mathrm{OAc}$ and were placed in a mechanical shaker for 2 hours. The extracts were filtered through Whatman 
No. 42 filter paper and were also analyzed by ICP-MS (PerkinElmer NexION 300X). Soil microbial activity was evaluated based on substrate utilization profiles that were established using BIOLOG EcoMicroPlate ${ }^{\mathrm{TM}}$ (Biolog, Hayward, CA, USA). Soil sample (5 g) was suspended in $0.1 \mathrm{M} \mathrm{NaH}_{2} \mathrm{PO}_{4}$ solution (pH 6) at a ratio of 1:9 (w/v). The soil suspension was diluted 1,000 -fold with $0.15 \mathrm{M} \mathrm{NaCl}$ and $100 \mu \mathrm{L}$ of the diluted suspension was inoculated into each well. The microplates were incubated at $28{ }^{\circ} \mathrm{C}$ and their absorbance was measured at an optical density of $590 \mathrm{~nm}$ using a Multiskan ${ }^{\mathrm{TM}}$ Go Microplate Spectrometer (ThermoFisher, USA) every $24 \mathrm{~h}$ for 6 days. The absorbance of the 31 substrates was used to calculate the average well color development (AWCD) and the values were plotted against the incubation period of the plate (Ultra et al., 2012). The Shannon-Weaver index and richness of bacterial communities were calculated based on the absorbance readings of the microplate wells after $96 \mathrm{~h}$ of incubation.

\subsection{Statistical Analysis}

The data on soil properties were analyzed statistically following the analysis of variance (ANOVA) and the mean differences among treatments were compared by Fisher's Least Significant Difference (LSD) using the statistical computer package program, R-Software. On the other hand, AWCD, richness, and Shannon-Weaver index were statistically analyzed using the IBM SPSS Statistics ver. 21 for Windows. Mean values per treatment were compared using two-way analysis of variance. Tukey's honestly significant difference was performed to determine significant differences $(P<0.05)$. The optical density data from the Biolog EcoMicroPlate ${ }^{\mathrm{TM}}$ were subjected to principal component analysis using SPSS.

\section{Results}

\subsection{Soil Chemical Characteristics}

The $\mathrm{pH}$ observed for all treatments was neutral to slightly alkaline and relatively lower compared to the control. Noticeable decrease in $\mathrm{pH}$ compared to the control was seen in soils treated with 50\% BCB and 50\% BCB +250 WV. The EC was highest in soils treated with $100 \%$ BCB (Table 2). However, the result was comparable to other treatments except that of $50 \% \mathrm{BCB}$.

A general trend was seen in total $\mathrm{C}$, available $\mathrm{P}$, exch. $\mathrm{Mg}$, exch. $\mathrm{Na}$, exch. $\mathrm{Ca}$, exch. $\mathrm{K}$ and CEC (Table 2) with the highest values obtained in control treatment. In terms of total $\mathrm{C}$ content, there were no significant differences observed among treatments. The data on available $\mathrm{P}$, exch. $\mathrm{Mg}$, exch. $\mathrm{Na}$, exch. $\mathrm{Ca}$, exch. $\mathrm{K}$ and $\mathrm{CEC}$ revealed similar trends. Relatively lower values were obtained compared to the control (Table 2).

Table 2. Effect of herbicide and pyroligneous acid application on the chemical properties of soils under greenhouse conditions

\begin{tabular}{|c|c|c|c|c|c|c|c|c|c|}
\hline Treatments & $\mathrm{ph}$ & $\mathrm{EC}(u \mathrm{~S} / \mathrm{cm})$ & Total C (\%) & avail. $\mathrm{P}$ & exch. $\mathrm{Ca}$ & exch. Mg & exch. K & exch. $\mathrm{Na}$ & $\begin{array}{l}\text { CEC } \\
\left(\mathrm{cmol}_{\mathrm{c}} \mathrm{kg}^{-1} \text { soil }\right)\end{array}$ \\
\hline & & & & -------- & -------- & -----ppm- & ---- & ----------- & \\
\hline Control & $7.70 \mathrm{a}$ & $162.83 \mathrm{ab}$ & $0.39 \mathrm{a}$ & $10.32 \mathrm{a}$ & $4.57 \mathrm{a}$ & $1.41 \mathrm{a}$ & $0.12 \mathrm{a}$ & $0.40 \mathrm{a}$ & $6.49 \mathrm{a}$ \\
\hline $100 \mathrm{WV}$ & $7.30 \mathrm{ab}$ & $141.10 \mathrm{ab}$ & $0.32 \mathrm{a}$ & $7.87 \mathrm{~b}$ & $3.69 \mathrm{~b}$ & $1.02 \mathrm{~b}$ & $0.10 \mathrm{ab}$ & $0.33 \mathrm{~b}$ & $5.14 \mathrm{~b}$ \\
\hline $50 \%$ BCB & $7.28 \mathrm{~b}$ & $119.37 \mathrm{~b}$ & $0.29 \mathrm{a}$ & $6.89 \mathrm{~b}$ & $3.48 \mathrm{~b}$ & $0.98 \mathrm{~b}$ & $0.10 \mathrm{ab}$ & $0.31 \mathrm{~b}$ & $4.87 \mathrm{~b}$ \\
\hline $100 \% \mathrm{BCB}$ & $7.50 \mathrm{ab}$ & $163.10 \mathrm{a}$ & $0.29 \mathrm{a}$ & $7.80 \mathrm{~b}$ & $3.90 \mathrm{ab}$ & $1.05 \mathrm{~b}$ & $0.08 \mathrm{~b}$ & $0.33 \mathrm{~b}$ & $5.37 \mathrm{ab}$ \\
\hline $\begin{array}{l}50 \% \mathrm{BCB}+100 \\
\mathrm{WV}\end{array}$ & $7.46 \mathrm{ab}$ & $131.50 \mathrm{~b}$ & $0.29 \mathrm{a}$ & $7.72 \mathrm{~b}$ & $3.68 \mathrm{~b}$ & $1.02 \mathrm{~b}$ & $0.10 \mathrm{ab}$ & $0.31 \mathrm{~b}$ & $5.11 \mathrm{~b}$ \\
\hline $\begin{array}{l}50 \% \mathrm{BCB}+250 \\
\mathrm{WV}\end{array}$ & $7.17 \mathrm{~b}$ & $122.73 \mathrm{ab}$ & $0.31 \mathrm{a}$ & $6.14 \mathrm{~b}$ & $3.54 \mathrm{~b}$ & $0.96 \mathrm{~b}$ & $0.11 \mathrm{ab}$ & $0.31 \mathrm{~b}$ & $4.93 \mathrm{~b}$ \\
\hline $\begin{array}{l}50 \% \mathrm{BCB}+500 \\
\mathrm{WV}\end{array}$ & $7.30 \mathrm{ab}$ & $128.57 \mathrm{ab}$ & $0.31 \mathrm{a}$ & $7.66 \mathrm{~b}$ & $3.26 \mathrm{~b}$ & $0.92 \mathrm{~b}$ & $0.09 \mathrm{ab}$ & $0.30 \mathrm{~b}$ & $4.57 \mathrm{~b}$ \\
\hline
\end{tabular}

\subsection{Soil Biological Characteristics}

The highest AWCD on the Biolog EcoMicroplate ${ }^{\mathrm{TM}}$ was observed under $50 \% \mathrm{BCB}+500 \mathrm{WV}$ treatment after 4 days of incubation which indicates high microbial activity (Figure 1). In addition, an increased activity of soil microorganisms was also observed in the control. On the other hand, lower AWCD was observed in the 100\% $\mathrm{BCB}$ treatment. A noticeable decrease in microbial activity was observed in $50 \% \mathrm{BCB}+250 \mathrm{WV}$. This suggests 
that treatment combination synergistically affected the soil microorganisms. In terms of Shannon-Weaver index, there were no noticeable differences among treatments (Figure 2). However, a significant difference was observed in richness which was attributed to the $50 \%$ BCB treatment (Figure 3).

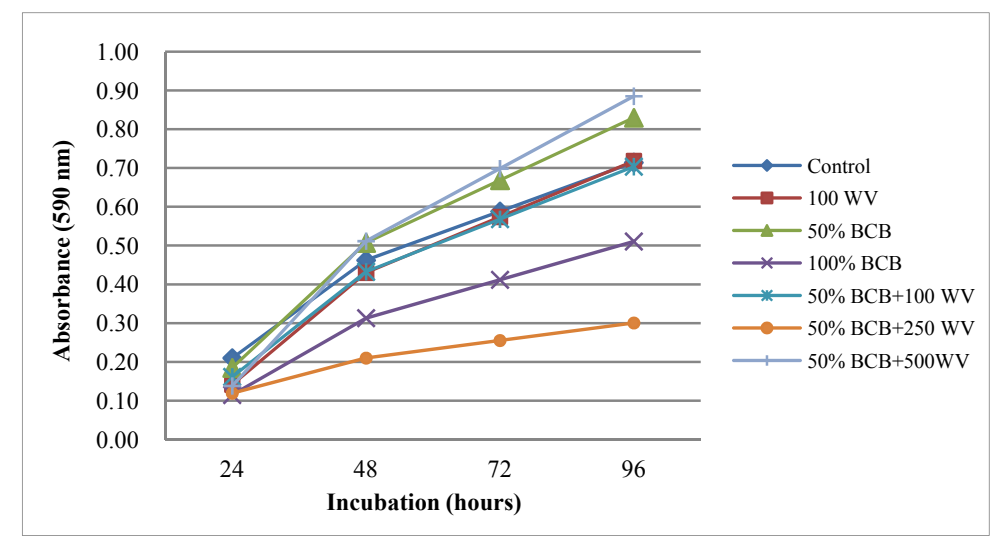

Figure 1. Effect of herbicide x pyroligneous acid application on the Average Well Color Development (AWCD) based on Biolog Ecomicroplate ${ }^{\mathrm{TM}}$ absorbance data of soils under greenhouse conditions

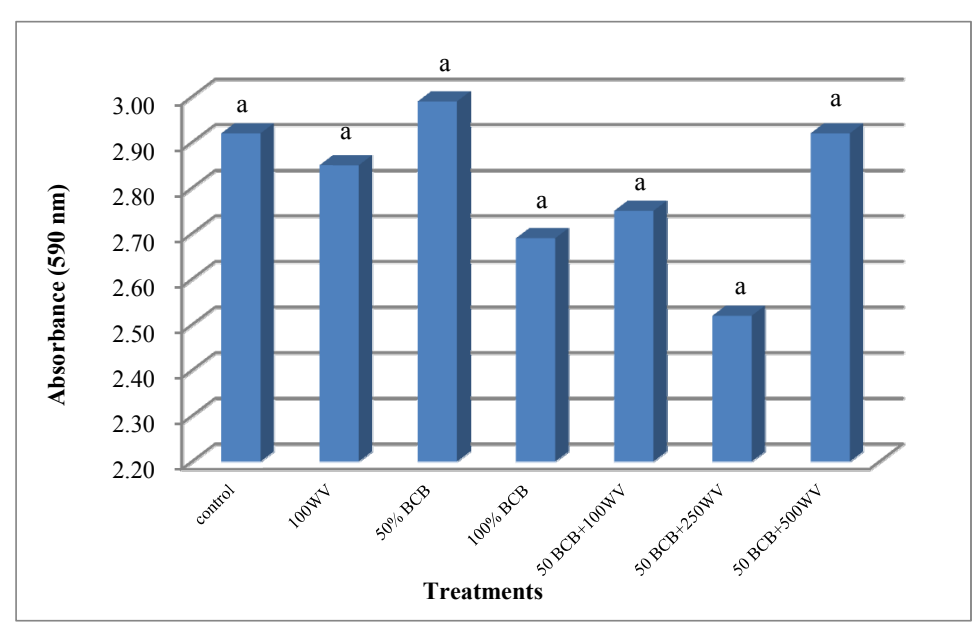

Figure 2. Influence of herbicide x pyroligneous acid application on the Shannon-Weaver index of soils based on Biolog EcoMicroplate ${ }^{\mathrm{TM}}$ absorbance data at $96 \mathrm{~h}$ of incubation. Same letters indicate non significant differences according to Tukey's test $(P \leq 0.05)$ 


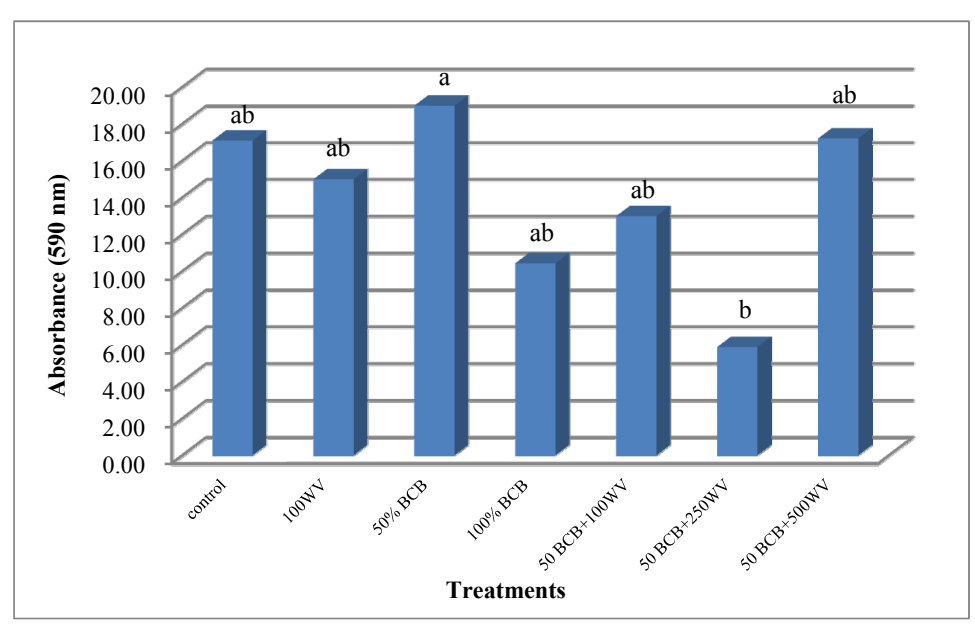

Figure 3. Richness of metabolized carbon of soils as affected by herbicide $\mathrm{x}$ pyroligneous acid application based on Biolog EcoMicroplate ${ }^{\mathrm{TM}}$ absorbance data at $96 \mathrm{~h}$ of incubation. Same letters indicate non significant differences according to Tukey's test $(P \leq 0.05)$

The Biolog EcoMicroplate ${ }^{\mathrm{TM}}$ readings at 96 hours were subjected to principal component analysis (PCA) to determine the extent of differentiation of microbial functional structure based on the carbon source utilization among soils from different treatments. This resulted in the extraction of 3 principal components (PC) contributing about $25 \%, 17 \%$, and $10 \%$ to the data variance, corresponding to $\mathrm{PC} 1, \mathrm{PC} 2$, and $\mathrm{PC} 3$, respectively (Figure 4). The plots between $\mathrm{PC} 1$ and $\mathrm{PC} 2$ scores were able to differentiate the soil treated with $50 \% \mathrm{BCB}+250$ WV from other treatments (Figure 4a). On the other hand, the plots of PC1 and PC3 scores were able to differentiate the soils from the control and 50\% BCB from other treatments (Figure $4 \mathrm{~b}$ ).

The carbon substrates were most heavily loaded based on the principal component analysis (Table 3). Twelve carbon substrates contributed to the separation of treatments along PC1. The highest utilization of these substrates was observed in $50 \% \mathrm{BCB}+500 \mathrm{WV}$ treatment. The carbohydrate D-mannitol was highly utilized by the microorganisms in all treatments except for $50 \% \mathrm{BCB}+250 \mathrm{WV}$ treatment. The carbon substrate distinct to PC2 was D-cellobiose which was highly utilized under the treatment combination $50 \% \mathrm{BCB}+250 \mathrm{WV}$. The substrates unique to PC3 were 4-hydroxy benzoic acid, glycyl-L-glutamic acid, $\alpha$-cyclodextrin, and glycogen, which in general, were less utilized as seen in all treatments. 

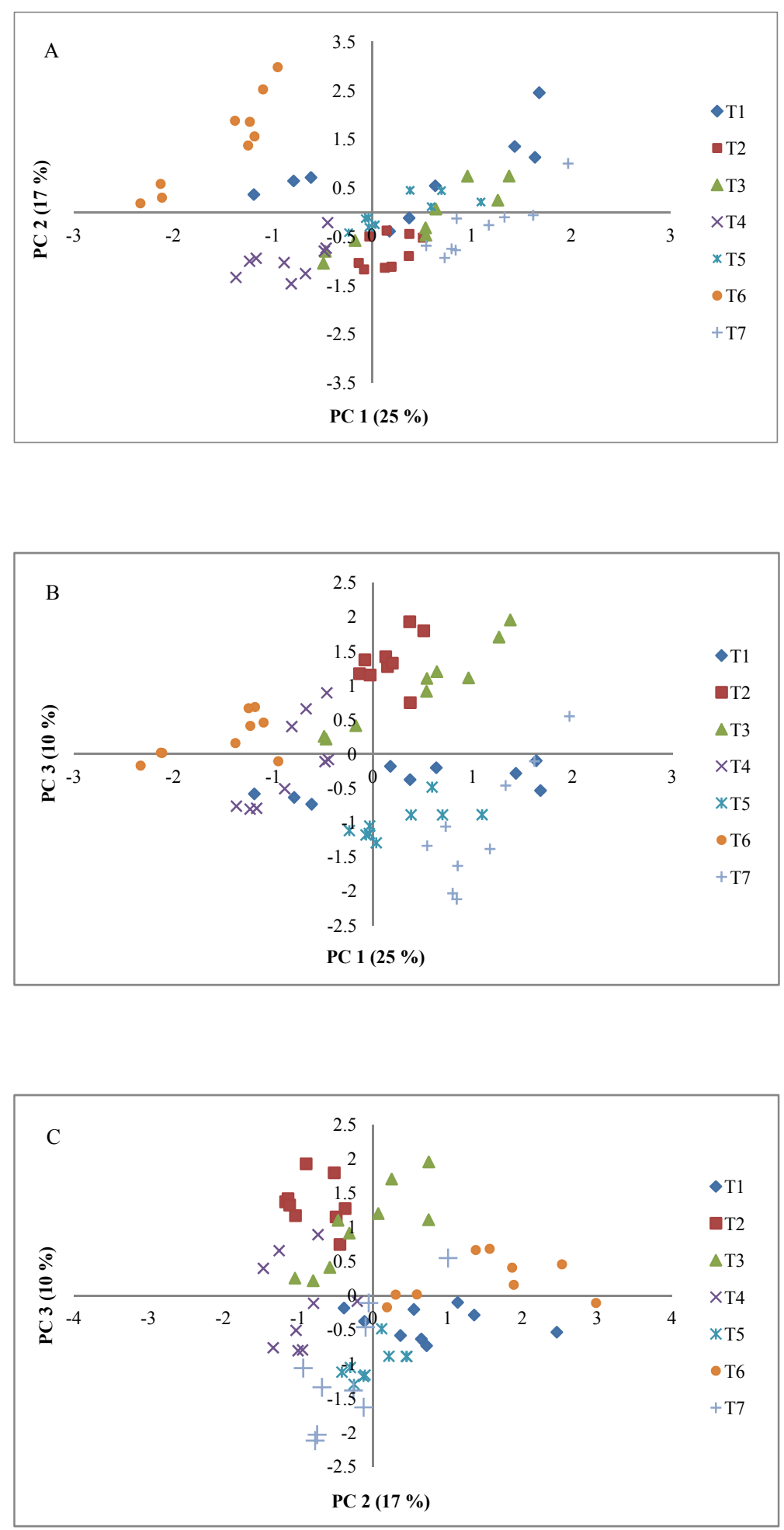

Figure 4. Principal component analysis based on the carbon source utilization among soils from different treatments (T1 - $100 \mathrm{WV}, \mathrm{T} 2-$ Control, $\mathrm{T} 3-50 \% \mathrm{BCB}, \mathrm{T} 4-100 \% \mathrm{BCB}, \mathrm{T} 5-50 \% \mathrm{BCB}+100 \mathrm{WV}, \mathrm{T} 6-50 \%$ $\mathrm{BCB}+250 \mathrm{WV}$ and $\mathrm{T} 7-50 \% \mathrm{BCB}+500 \mathrm{WV}$ ) 
Table 3. Carbon substrates most heavily loaded based on the principal component analysis

\begin{tabular}{|c|c|c|c|}
\hline Carbon substrates & PC 1* & PC 2* & PC $3 *$ \\
\hline \multicolumn{4}{|l|}{ Carboxylic acids } \\
\hline$\gamma$-hydroxy butyric acid & .580 & & \\
\hline D-galactonic acid $\gamma$-lactone & & .616 & \\
\hline 2-hydroxy benzoic acid & & .710 & \\
\hline$\alpha$-keto butyric acid & & .727 & \\
\hline 4-hydroxy benzoic acid & & & .752 \\
\hline \multicolumn{4}{|l|}{ Carbohydrates } \\
\hline$\beta$-methyl-D-glucoside & .738 & & \\
\hline i-erythritol & .527 & & \\
\hline D-mannitol & .707 & & \\
\hline N-acethl-D-glucosamine & .846 & & \\
\hline$\alpha$-D-lactose & .597 & .527 & \\
\hline D-xylose & & .798 & \\
\hline D-cellobiose & & .505 & \\
\hline \multicolumn{4}{|l|}{ Amino acids } \\
\hline L-arginine & .516 & & \\
\hline L-asparagine & .776 & & \\
\hline L-serine & .777 & & \\
\hline L-phenylalanine & & .659 & \\
\hline Glycyl-L-glutamic acid & & & .720 \\
\hline \multicolumn{4}{|l|}{ Polymers } \\
\hline Tween 40 & .687 & & \\
\hline$\alpha$-cyclodextrin & & & .512 \\
\hline Glycogen & & & .761 \\
\hline \multicolumn{4}{|l|}{ Amines } \\
\hline Phenylethyl-amine & .625 & & \\
\hline Putrescine & & -.578 & \\
\hline Phosphorylated chemical & .707 & & \\
\hline
\end{tabular}

Note. $*$ PC 1, PC 2 and PC 3 are the principal components extracted from the principal component analysis (PCA) of the microbial community substrate utilization potential of herbicide-wood vinegar treated soils.

Table 4. Correlation analysis between the chemical and biological properties of soils applied with herbicide and wood vinegar

\begin{tabular}{llllll}
\hline Properties & PC1 & PC2 & PC3 & Richness & Shannon-Weaver Index \\
\hline $\mathrm{EC}$ & -.003 & -.372 & .226 & .056 & .086 \\
$\mathrm{pH}$ & .091 & $-.547^{*}$ & .246 & .242 & .255 \\
Total C & .352 & .157 & $.475^{*}$ & .320 & .404 \\
$\mathrm{P}$ & .136 & $-.519^{*}$ & .231 & .276 & .175 \\
$\mathrm{Ca}$ & .090 & -.073 & $.490^{*}$ & .125 & .236 \\
$\mathrm{Mg}$ & .147 & -.178 & $.555^{* *}$ & .234 & .309 \\
$\mathrm{Na}$ & .122 & -.077 & $.489^{*}$ & .171 & .282 \\
$\mathrm{~K}$ & .085 & .388 & .243 & .048 & .119 \\
$\mathrm{CEC}$ & .107 & -.089 & $.517^{*}$ & .155 & .260 \\
\hline
\end{tabular}

Note. ${ }^{* \mathrm{P}<0.05 ; * * \mathrm{P}<0.01}$. 


\section{Discussion}

\subsection{Soil Chemical Characteristics}

The experimental set up mimicked a paddy soil condition wherein the soil was under waterlogged conditions. The soil system was generally quite buffered to the extent that waterlogging was not effective in changing the $\mathrm{pH}$, though it has been known that in waterlogged soil, anaerobic conditions take place and as a result fermentation of carbohydrates occur releasing acids which shift the $\mathrm{pH}$ to the acidic side (Taha et al., 1967). In addition, the decrease in $\mathrm{pH}$ can be attributed to the acidic nature of wood vinegar and herbicides.

The lower values obtained in total $\mathrm{C}$, available $\mathrm{P}$, exch. $\mathrm{Mg}$, exch. $\mathrm{Na}$, exch. $\mathrm{Ca}$, exch. $\mathrm{K}$ and $\mathrm{C}$ can be attributed to wood vinegar. Wood vinegar has the ability to reduce the cluster value of water. This means that the water is activated and can be easily absorbed by the plants because water with a low cluster value is in a very small mass. Each of these masses will hold one or few mineral elements which can be easily taken up by plants (http://www.agrowingculture.org).

Lower P contents observed on the treatments could be related to fixation in the soil, since it was alkaline in reaction (Taha et al., 1967). Phosphorous can be fixed in the form of calcium, magnesium, iron or aluminum phosphates and clay-adsorbed phosphorous (Mahdi et al., 2012). When alkaline soils were waterlogged, calcium phosphates and aluminum phosphates increased while iron phosphates decreased (IRRI, 1978). The best availability of phosphorous is in the range of $\mathrm{pH} 6.0$ to 7.0. According to Foth (1978), calcium phosphates begin to precipitate at about $\mathrm{pH}$ 6.0. On the contrary, above $\mathrm{pH}$ 7.0, there is a reduction in phosphorus solubility or availability. Increases in $\mathrm{pH}$ above 7.0 create sufficient $\mathrm{OH}^{-}$to react with $\mathrm{H}_{2} \mathrm{PO}_{4}{ }^{-}$to form $\mathrm{HPO}_{4}{ }^{2-}$ and water to cause the latter form of phosphorus to become the most abundant. Since $\mathrm{HPO}_{4}{ }^{2-}$ is less readily taken up by plants than $\mathrm{H}_{2} \mathrm{PO}_{4}{ }^{-}$, one can conclude that part of the reduced availability of phosphorus in alkaline soils is due to the presence of hydroxyl ions and formation of $\mathrm{HPO}_{4}{ }^{2-}$. The chemical components of the wood vinegar may have contributed to the production of $\mathrm{OH}^{-}$reacting with $\mathrm{H}_{2} \mathrm{PO}_{4}{ }^{-}$resulting to unavailable forms of phosphorus (Foth, 1978). In addition, soluble $\mathrm{H}_{2} \mathrm{PO}_{4}{ }^{-}$quickly reacts with calcium to form a sequence of products of decreasing solubility (Mahdi et al., 2012).

\subsection{Soil Biological Characteristics}

The high microbial activity observed under $50 \% \mathrm{BCB}+500 \mathrm{WV}$ treatment could be attributed to low levels of herbicide and wood vinegar. The low concentrations of alcohols, acids, and aldehydes in the wood vinegar served as carbon and energy substrates for soil microorganisms (Steiner et al., 2008). The increased microbial activity under the control treatment was probably due to root exudates released by barnyard grass which provide nourishment to the soil microflora. In contrast, application of $100 \%$ BCB decreased the activity of soil microorganisms. This reduction in microbial activity, coinciding with withering plant biomass, could have resulted from drastically reduced root exudates that serve as a resource of the microorganisms in the soil. A shortage in root exudates can lead the rhizosphere microbes to enter a dormant, inactive stage (Hagner, 2013). Therefore, a decline in microbial activity can be observed. This also indicates that $100 \%$ application of herbicides is detrimental to soil microorganisms. The Shannon-Weaver index and richness were obtained after 96 hours of incubation. The Shannon-Weaver index is an indicator of the microbial functional diversity in soil. On the other hand, richness refers to the carbon utilization by microorganisms. Based on the results, all treatments did not significantly affect the microbial functional diversity in soil. However, a significant difference was observed in richness which was attributed to $50 \% \mathrm{BCB}$ treatment. This can be a reflection of the availability of nutrients in the soil that were utilized by microorganisms. In general, herbicides affect soil microbes indirectly. They can be a source of nutrition for microbes or when applied in high doses, may kill microorganisms. The lower rate of BCB application and also its combination with $500 \mathrm{WV}$ favored microbial activity in the soil. Related studies showed that microbes propagate well when higher dilution of wood vinegar was applied. An experiment conducted by Steiner et al. (2008) revealed significant increase in microbial biomass and population growth rate when PA was applied in highly weathered soils. This is mainly due to the effect on the metabolism by acetic acid. Acetyl co-enzyme is produced by plants and microbes from acetic acid. Through the TCA cycle, acetyl co-enzyme is converted into citridic acid, malic acid, fumaric acid, succiric acid and other elements that are necessary for the plants and microbes (Nelson \& Cox, 2012). This is the main reason behind the propagation of microbes. The herbicide and wood vinegar may have worked synergistically for microbial growth and multiplication (http://www.agrowingculture.org).

The variability in PC1 can be explained by the high utilization of five carbohydrates and three amino acids. The carbohydrates include $\beta$-methyl-D-glucoside, i-erythritol, D-mannitol, N-acetyl-D-glucosamine and $\alpha$-D-lactose. On the other hand, L-arginine, L-asparagine and L-serine are the amino acids responsible for the variation in 
PC1. Variability in the second PC can be attributed by responses to carboxylic acids, carbohydrates and amine (Table 3).

Correlation analysis between soil and microbial properties were also evaluated (Table 4). Results revealed that PC2 had negative correlation with $\mathrm{pH}$ and available P. This implies that the set of particular microbial communities that utilized the carbon substrates in the Biolog Microecoplate ${ }^{\mathrm{TM}}$ that contributed to PC 2 are pH-dependent and can be influenced by the availability of P. As cited by Bunemann et al. (2011) microorganisms require or preferentially use inorganic forms of $P$ tying up the nutrient in microbial biomass, a process called immobilization. Microbial P immobilization can affect $\mathrm{P}$ availability by removing inorganic $\mathrm{P}$ from the soil solution, especially when soluble carbon is available for microbial growth. On the other hand, PC3 was positively correlated with total carbon, exch. $\mathrm{Ca}, \mathrm{Mg}, \mathrm{Na}$, and $\mathrm{CEC}$. The microbial communities that utilized the substrates that were distinct to PC 3 could be related to the availability of total carbon, exch. $\mathrm{Ca}, \mathrm{Mg}, \mathrm{Na}$, and CEC. This implies the role of mineral nutrition on microbial growth. The alteration of substrate quality due to the addition of wood vinegar triggered the shift of soil microbial functional structure.

\section{References}

Andrade, F. V. (2003). Adição de ácidos orgânicos e húmicos em Latossolos e adsorção de fosfato. Revista Brasileira de Ciência do Solo, 27(6), 1003-1011. http://dx.doi.org/10.1590/S0100-06832003000600004

Brix, H. (2008). Soil Exchangeable Bases (ammonium acetate method). Retrieved May 2, 2013, from http://mit.biology.au.dk/ biohbn/Protocol/Soil_Exchangeable_Bases_CEC_20081127.pdf

Bunemann, E. K., Oberson, A., \& Frossard, E. (2011). Phosphorus in Action. Soil Biology, 26, 37-57. http://dx.doi.org/10.1007/978-3-642-15271-9_2

Focht, U. (1999). The effect of smoke from charcoal kilns on soil respiration. Environmental Monitoring and Assessment, 59, 73-80. http://dx.doi.org/10.1023/A:1006010629482

Foth, H. D. (1978). Fundamentals of Soil Science. John Wiley \& Sons, Inc. USA.

Garcia-Oliva, F., Sanford, R. L., \& Kelly, E. (1998). Effect of burning of tropical deciduous forest soil in Mexico on the microbial degradation of organic matter. Plant Soil, 206, 29-36. http://dx.doi.org/10.1023/A:1004390202057

Giardina, C. P., Sanford, R. L., Dockersmith, I. C., \& Jaramillo, V. J. (2000). The effects of slash burning on ecosystem nutrients during the land preparation phase of shifting cultivation. Plant Soil, 220, 247-260. http://dx.doi.org/10.1023/A:1004741125636

Hagner, M. (2013). Potential of the slow pyrolysis products birch tar oil, wood vinegar and biochar in sustainable plant protection-pesticidal effects, soil improvement and environmental risks. Department of Environmental Sciences, University of Helsinki, Lahti, Finland.

International Rice Research Institute. (1978). Soils and rice. Los Baños, Philippines.

Jones, D. L. (1998). Organic acids in the rhizosphere - A critical review. Plant and Soil, 205(1), 25-44. http://dx.doi.org/10.1023/A:1004356007312

Kim, Y. H., Kim, S. K., Kim, K. S., \& Lee, Y. H. (2001). Composition of constituents of commercial wood vinegar. Korea J. Agric. Chem. and Biotech., 44(4), 262-268.

Mahdi, S. S., Talat, M. A., Hussain Dar, M., Hamid, A., \& Ahmad, L. (2012). Soil phosphorus fixation chemistry and role of phosphate solubilizing bacteria in enhancing its efficiency for sustainable cropping - A review. Journal of Pure and Applied Microbiology, 6(4), 1-7.

Nelson, D. L., \& Cox, M. M. (2012). Lehninger Principles of Biochemistry (6th ed.). W. H. Freeman \& Company. New York.

Pierzynski, G. M. (2000). Methods of Phophorus Analysis for Soils, Sediments, Residuals, and Waters. Southern Cooperative Series Bulletin, 396, 13-14.

Souza, J. B. G., Re-Poppi, N., \& Raposo Jr., J. L. (2012). Characterization of pyroligneous acid used in Agriculture by Gas Chromatography-Mass Spectrometry. J. Brazil. Chem. Soc., 23(4), 610-617.

Steiner, C., Das, K. C., Garcia, M., Forster, B., \& Zech, W. (2008). Charcoal and smoke extract stimulate the soil microbial community in a highly weathered xanthic Ferralsol. Pedobiologia, 51, 359-366. http://dx.doi.org/10.1016/j.pedobi.2007.08.002

Stenstrom, J., Stenberg, B., \& Johanson, M. (1998). Kinetics of substrate-induced respiration (SIR): Theory. 
Ambio, 27, 35-39.

Taha, S. M., Mahmoud, S. A. Z., \& Ibrahim, A. N. (1967). Microbiological and Chemical Properties of Paddy Soil. Plant and Soil, 26, 1. http://dx.doi.org/10.1007/BF01978674

Ultra, V. U., Han, S. H., \& Kim, D. H. (2012). Soil properties and microbial functional structure in the rhizosphere of Pinus densiflora (S. and Z.) exposed to elevated atmospheric temperature and carbon dioxide. Journal of Forest Research, 18(2), 149-158. http://dx.doi.org/10.1007/s10310-012-0333-6

\section{Copyrights}

Copyright for this article is retained by the author(s), with first publication rights granted to the journal.

This is an open-access article distributed under the terms and conditions of the Creative Commons Attribution license (http://creativecommons.org/licenses/by/3.0/). 